\title{
Wind Tunnel Flutter Testing of Composite T-Tail Model of a Transport Aircraft with Fuselage Flexibility
}

\author{
Raja Samikkannu ${ }^{1}$ and A. R. Upadhya ${ }^{2}$ \\ ${ }^{1}$ Scientist, \\ ${ }^{2}$ Director, \\ National Aerospace Laboratories (CSIR-NAL), \\ Bangalore, \\ India
}

\section{Introduction}

Aeroelasticity is the study of interaction among aerodynamic, inertial and elastic forces. Flight vehicles experience steady and unsteady aerodynamic loads; accordingly they would develop different kinds of stability and response related problems. Transonic aeroelastic problems such as buffet and flutter have been solved through experimental techniques at National Aerospace Laboratories (Upadhya et al., 1985), (Joshi et al., 1988), (Ramamurthy and Raja, 2002), (Raja et al., 2007). Figure 1 shows the aeroelastic models that were tested in $1.2 \mathrm{~m}$ wind tunnel. Aeroelastic flutter is a catastrophic structural failure, which needs to be avoided within the flight envelope of an aircraft for safe operation and enhanced fatigue life (FAR AC 25.629-1A). Aircraft structures made of thin walled sections and composite materials are usually lightly damped systems. When the orthogonality of elastic modes in such systems is influenced by the unsteady aerodynamic forces, the aerodynamic damping destabilizes the vibration, meaning the structural modes may draw energy from the air stream. Frequency and damping change due to aerodynamic energy may cause coupling between two or more adjacent modes to develop a flutter in the aircraft wing or tail structure. Flutter is a divergent oscillation that may result into fatal structural failure.

Low speed aircrafts need clean airflow over the tail surfaces to have better pitch control. Therefore a T-Tail configuration is preferred for such flying machines due to its geometric location. Aircrafts with T-Tail structure are in operation; for example Boeing 727, ATR-72, Q400, CRJ700 and Embaraer ERJ145 etc. Nevertheless, aeroelastic problems such as flutter and gust are of great concern for the designers because the structurally heavy vertical stabilizer needs to carry the lift producing horizontal tail, which makes T-Tail a structure of concern in the low speed aircraft (Bisplinghoff et al., 1983). The present research work addresses the TTail flutter of a transport aircraft within its flight envelope through a wind tunnel study. The T-Tail configuration is normally expected to develop a dynamic coupling among its horizontal and vertical stabilizers' modes and participate in the aeroelastic flutter along with the control surface modes (Rudder, Elevators). Since for the aircraft under consideration (transport), the fuselage flexibility is appeared to be very significant on the empennage 
flutter, a scaled T-Tail wind tunnel model has been designed with a flexible fuselage. Unlike the conventional horizontal tail plane, the horizontal tail sits on the top of a flexible fin in TTail, therefore may experience rolling, yawing and spanwises in-plane motion, in addition to pitching and plunging.

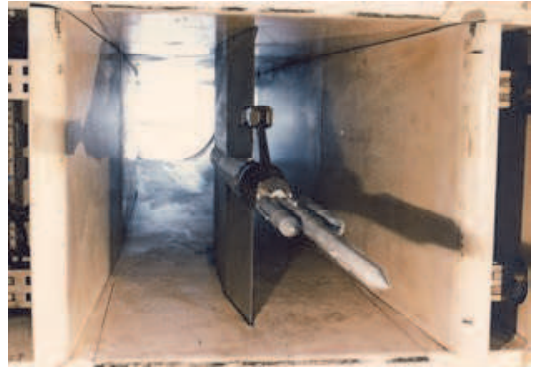

(a)

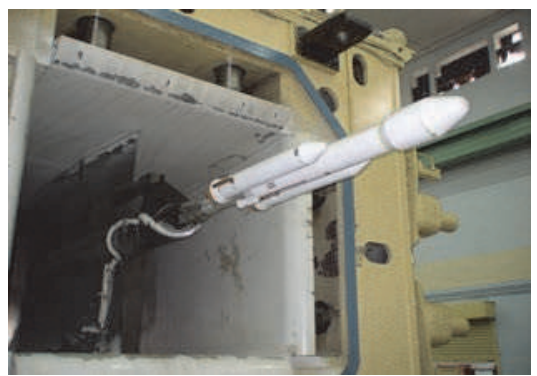

(c)

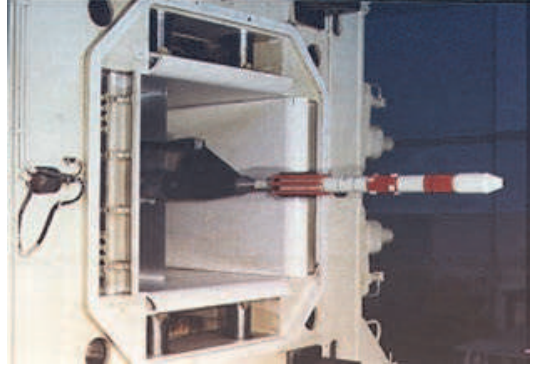

(b)

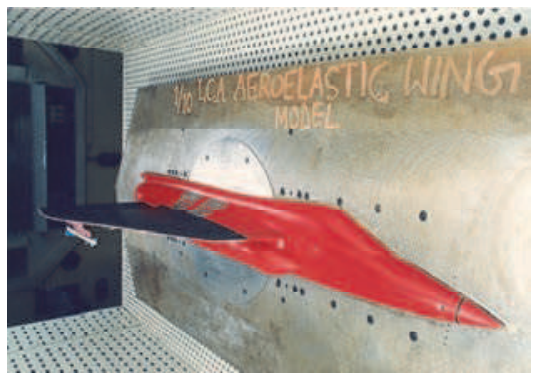

(d)

Fig. 1. Aeroelastic models in 1.2 m NAL trisoninc tunnel

Thus, in-plane loads and normal loads due to in-plane motion become important while calculating T-Tail flutter, which can be easily captured through wind tunnel testing. Otherwise, an improved DLM (Doublet Lattice Method) code is required that accounts for all the aerodynamic degrees of freedom in the calculation of flutter. Further the incremental aerodynamic loads due to roll and yaw acting on the horizontal tail plane are dependent on the steady aerodynamic loads; therefore inclusion of steady loads in the flutter analysis is important (Queijo, 1968). Thus, the present experimental approach to build an aeroelastically scaled T-Tail model with a flexible fuselage to estimate empennage flutter appears to be convincing.

However, it has become a challenging design issue to introduce fuselage longitudinal bending due to a sting supported system and further the simulation of multi-modes coupling. A novel idea is then commenced into the model design scheme to incorporate the fuselage bending along with the sting bending mode. Composite materials are employed to realise the structural components of the T-Tail and fuselage structure. The model is subsequently instrumented with strain gauges and accelerometers to measure the aeroelastic responses during the wind tunnel testing. The flutter characteristics are then presented in velocity versus frequency and velocity versus damping format. 


\section{Design of scaled aeroelastic model}

The aeroelastic model consists of the following components:

- Horizontal tail and elevators

- Vertical tail and rudder

- Torsion box assembly to attach the spars of the vertical tail

- Flexible fuselage

- Model supporting system

The results obtained from the wind tunnel testing are acceptable, only if the model simulates both aerodynamic and structural dynamic characteristics with respect to full scale vehicle (Bisplinghoff et al., 1983), (Megson T. H. G., 2007). This is achieved through a set of dynamic similarity laws, known as aeroelastic scale factors (Refer to table 1). A dynamically similar model only simulates frequencies and mode shapes. In contrast, an aeroelastically similar model additionally replicates the aerodynamic configuration of the vehicle. The aircraft model has been tested in $1.2 \mathrm{~m}$ wind tunnel. Figure 2 displays the side view of the model along with its sting mounting support system.

\begin{tabular}{ll}
\hline Geometric scale ratio & $\mathrm{L}=\mathrm{Lm} / \mathrm{Lp}$ \\
Dynamic pressure ratio & $\mathrm{q}=\mathrm{qm} / \mathrm{qp}$ \\
Density ratio & $\rho=\rho \mathrm{m} / \rho \mathrm{p}$ \\
Velocity ratio & $\mathrm{V}=\mathrm{Vm} / \mathrm{Vp}$ \\
Weight ratio & $\mathrm{W}=\mathrm{Wm} / \mathrm{Wp}$ \\
Frequency ratio & $\Omega=\Omega \mathrm{m} / \Omega \mathrm{p}$ \\
Deflection ratio & $\delta=\delta \mathrm{m} / \delta \mathrm{p}$ \\
Flexural Stiffness ratio & $(\mathrm{EI}) \mathrm{m} /(\mathrm{EI}) \mathrm{p}$ \\
Axial Stiffness ratio & $(\mathrm{EA}) \mathrm{m} /(\mathrm{EA}) \mathrm{p}$ \\
\hline
\end{tabular}

Table 1. Aeroelastic scale parameters

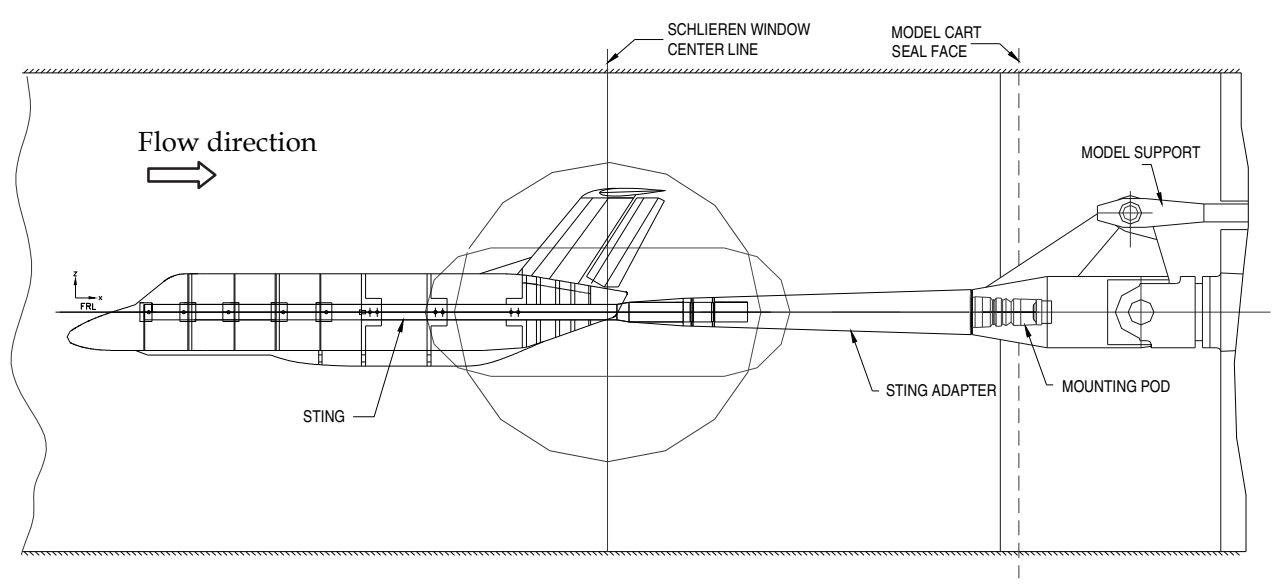

Fig. 2. Aircraft model with a sting support system 
In order to accommodate the model in the test section of the wind tunnel, a $10 \%$ geometric scale is chosen for the specified test condition. Proper care is taken to minimize the blockage area (around 2\%), so that there will not be any starting problem for the tunnel. Accordingly, the aeroelastic scale factors have been arrived for a fair representation of the mathematical analogue of the physical system, considering the fluid - structure interaction.

\subsection{Model design details}

Flight conditions such as flight dynamic pressure, flight altitude, air density, flight velocity and Mach number are taken as reference data for the design process. As a first step, suitable scale factors are derived, which would suit the model characteristics to the existing wind tunnel characteristics. The blow down type wind tunnel has limitation in terms of its test section, achievable dynamic pressure and run time etc. Therefore the geometric scale and dynamic pressure ratio are mostly the deciding factors to set the aeroelastic scales. The TTail model is designed following a replica design logic, in which a spar-rib-skin arrangement is maintained. Further, the same number of spars as in the full scale vehicle is considered at the model level. However the number of ribs is taken according to the model stiffness requirement. Figures 3, 4 present the design details of both horizontal tail plane (HTP) and vertical tail plane (VTP), respectively. HTP is constructed with two spars and VTP is made using three spars arrangement. All dimensions are given in $\mathrm{mm}$. The control surfaces (elevators, rudder) are also built with spar-rib-skin construction. Fuselage is designed with metallic/composite bulkheads and stiffeners, over which a composite skin (CFRP) is provided (Refer to figure 5).

Due care is taken in the selection of appropriate materials for making the model, considering the feasibility of fabrication and availability of materials. The designed model has got nearly $70 \%$ composite components (CFRP) and the remaining is metallic. The model is required to be mounted in the specified test section of the wind tunnel, so that the T-Tail is exposed to a set and necessary flow characteristics such as Mach number, dynamic pressure etc. Therefore a sting adapter is introduced into the model supporting system (Figure 2). Thus, the designed T-Tail is pushed forward to experience the actual and set wind tunnel flow characteristics. Because of this increased exposure length of the sting, there is a need to provide sufficient torsional stiffness in order to ensure the stability and strength of the fuselage. Hence five additional CFRP disc type bulk heads have been incorporated in the front fuselage along with a CFRP tubular structure as core, which gets connected to the sting.

\subsection{Design details of joints for sub-structural systems}

To build an efficient aeroelastic T-Tail model, the joint flexibility of all the sub-structural systems must be appropriately simulated. Figure 6 (a, b, c, d) depicts the various joints, which are designed to integrate all the sub-systems. For example the control surfaces (elevator, ruder) are connected to the main surfaces with the help of torque tubes, designed to provide the required control-circuit stiffnesses.

By ensuring a proper rotational stiffness, the ruder and elevator fundamental modes are simulated.

The elevator torque tube has connected to both left and right elevators, so that they act as a single control surface. The spars of VTP are positioned in a torsion box assembly (figure 5d), in order to reproduce the necessary flexibility as in the full scale vehicle. 


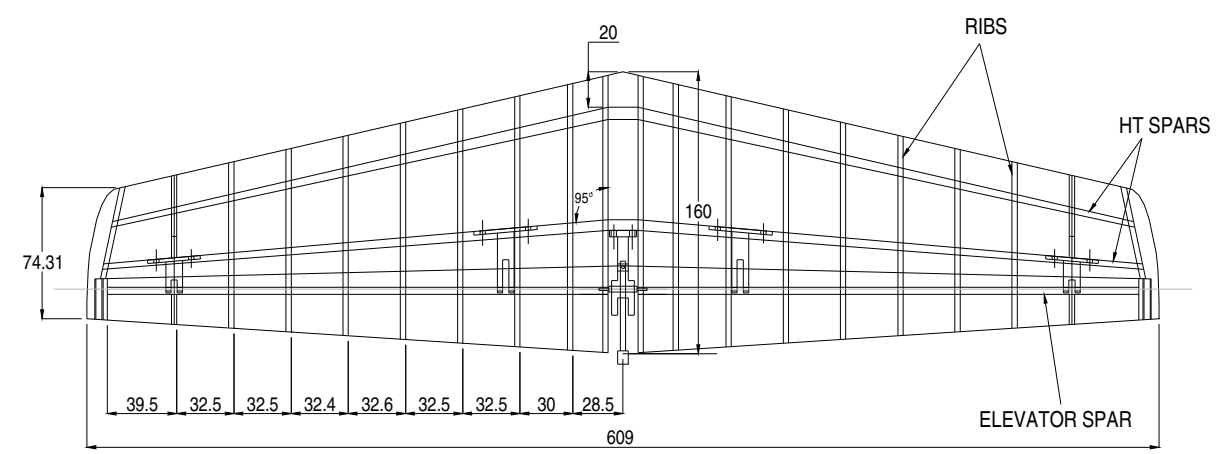

Fig. 3. Horizontal tail plane assembly

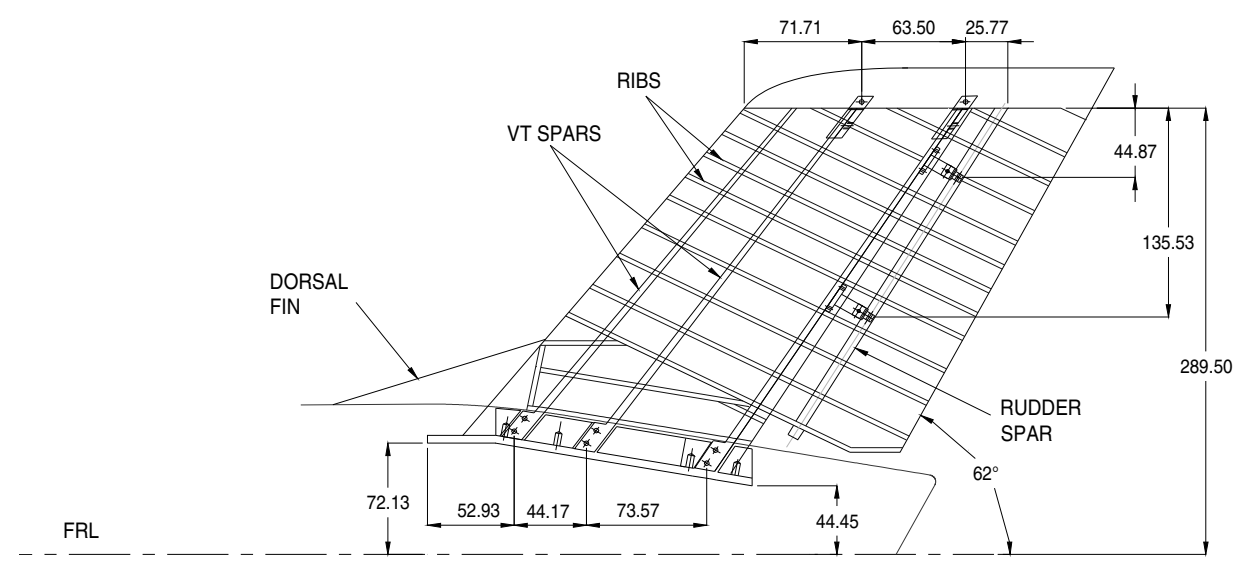

Fig. 4. Vertical tail plane assembly

\subsection{Model fabrication and integration}

After freezing the design, the production drawings are prepared using AUTOCAD 2000. The composite components are fabricated by using appropriate moulds. Skin/bulkhead/spar type of construction is adopted for fabricating the $10 \%$ fuselage. Along its length, the model fuselage consists of two circular aluminium rings, seven aluminium disc type bulkheads and five composite discs (not shown in figure 5). The skeleton is further stiffened using sets of side and top spars made of aluminium. CFRP skin of uniform thickness is fabricated in two halves using hand lay-up process and cured at room temperature. Nearly $40 \%$ resin content is achieved in the cured component.

VTP is constructed in spar-rib-skin form. It has got three aluminium spars and eighteen balsa ribs (refer to figure 4). A uniform thickness CFRP skin (top \& bottom) is made to get the required aerodynamic shape. The mould is built in such a way that it could accommodate as well the rudder skin. Further, the rudder is constructed using a single aluminium spar with balsa ribs and CFRP skin. In a similar way HTP moulds (top and bottom) are fabricated first, which have got provision to include elevator skin. HTP is made 


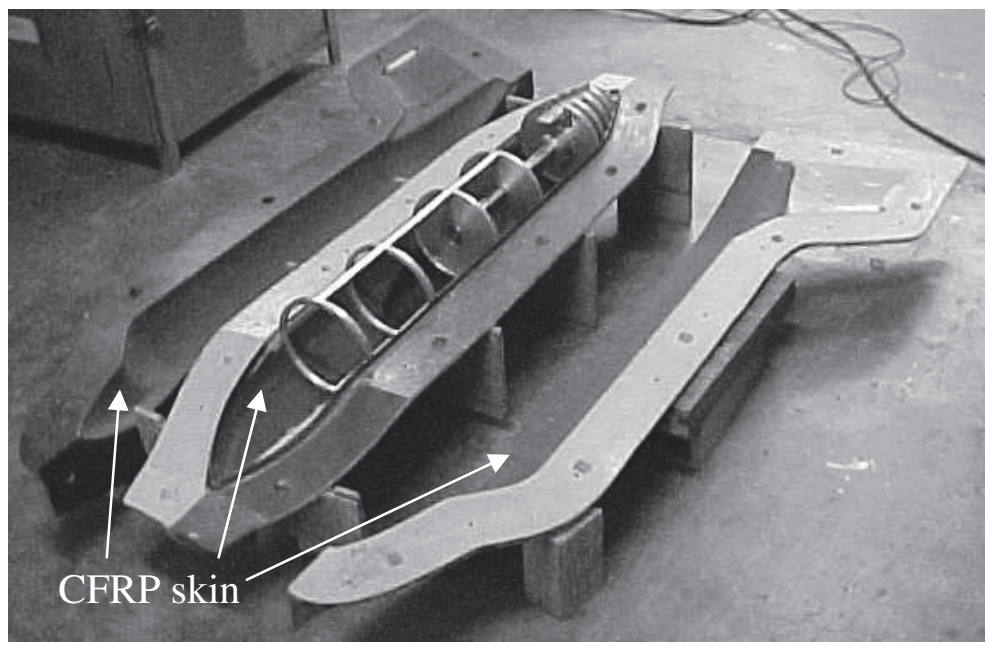

Fig. 5. Fuselage skin, bulk heads, and stiffeners with mould

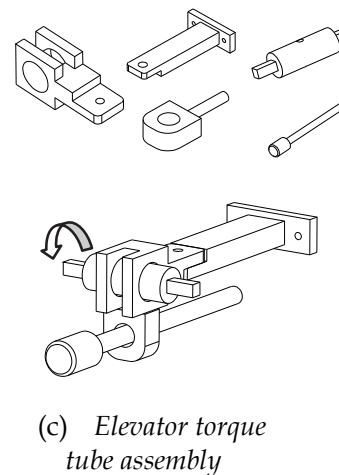

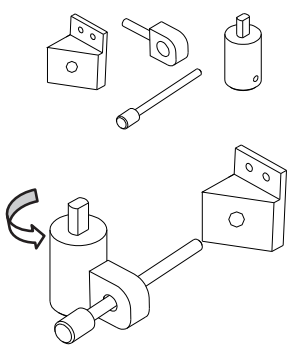

(d) Rudder torque
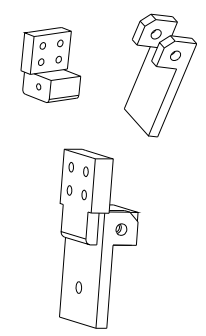

(b) $H T-V T$

hinge

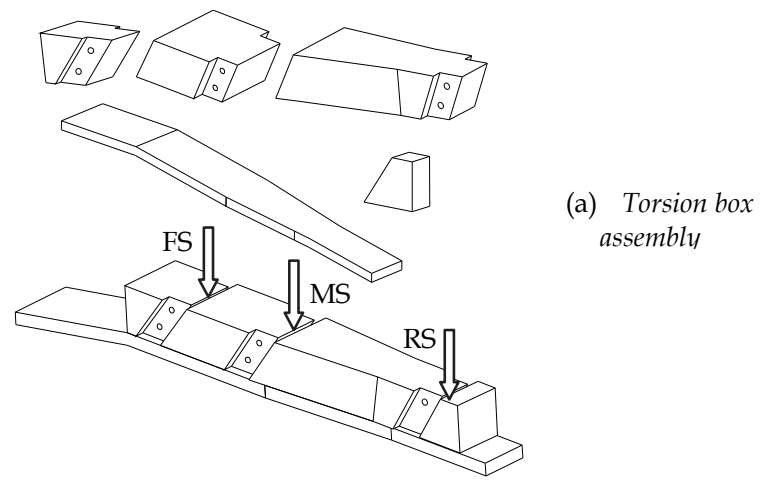

Fig. 6. Mechanical joints for structural components integration and flexibility simulation 
of two aluminium spars with twenty balsa ribs (refer to figure 3). A uniform CFRP skin is provided in two parts (top \& bottom) to give the required aerodynamic shape. The model supporting system essentially consists of a sting and an adapter. A sting with required strength and dimension is manufactured using EN24 material (Ultrasonic tested for flaws). Adapter is also fabricated with the same type of material, satisfying the strength adequacy requirements.

After the fabrication of major components (spar/rib/skin etc), each component is independently weighed and checked for its mass simulation. Hinges are fabricated using aluminium material for connecting the control surfaces to main surfaces. The assembled sub structural systems are weighed and checked for their required mass. The VTP spars are positioned inside the torsion boxes, which are mounted on the rear bulkheads of the fuselage. Then HTP assembly has been attached to VTP.

\section{Vibration analysis and test correlation}

A detailed free vibration analysis is performed on the designed T-Tail structure using MSCNASTRAN (refer to figure 7). The analysis is carried out attaching the fuselage at three support points with sting, which has been fixed at one end (simulating the tunnel sting mounted condition). The fabricated model is appropriately instrumented with accelerometers and strain gauges to measure the structural responses. After the instrumentation, the model is subjected to ground tests (both static and dynamic). Ground tests are essential for two reasons, one is to check the achieved accuracy of dynamic simulation and the second is to extract the static and dynamic characteristics of the model.

The Kyowa make strain gauges and PCB type accelerometers (sensitivity: $100 \mathrm{mv} / \mathrm{g}$ ) are used. The gauges are surface bonded and connected by using thin multi strand Teflon wires. Further they are numbered and terminated outside the model. Static tests are conducted by loading the structure at its $\mathrm{Cp}$ to monitor the strain output on the model at different locations to verify the model strength, as well as support system's ability to carry the model weight and the aerodynamic forces. The dynamic testing is subsequently performed from component level to fully assembled model. This exercise has helped to fine tune the dynamics of the integrated structure in a befitting way. However, the results are presented in a concise manner for the integrated model only (See table 2).

\begin{tabular}{|c|c|c|c|c|}
\hline \multirow{2}{*}{ ModeNo. } & \multicolumn{3}{|c|}{ Frequency (Hz) } & \multirow{2}{*}{ Remarks } \\
\cline { 2 - 4 } & $\begin{array}{c}\text { GVT } \\
\text { (proto) }\end{array}$ & $\begin{array}{c}\text { Experiment } \\
\text { (Model) }\end{array}$ & $\begin{array}{c}\text { FEM } \\
\text { (Model) }\end{array}$ & Rudder rotation \\
\hline 1 & 66.04 & 64.11 & 66.40 & Elevator rotation \\
\hline 2 & 102.65 & 100.28 & 102.8 & HT anti-symmetric bending \\
\hline 3 & 105.17 & 97.67 & 96.67 & VT longitudinal bending \\
\hline 4 & 149.50 & 149.92 & 151.1 & VT lateral bending \\
\hline 5 & 170.28 & 174.24 & 162.8 & HT symmetric bending \\
\hline 6 & 207.72 & 211.90 & 209.8 & Fuselage first longitudinal bending \\
\hline 7 & 281.49 & 327.23 & 285.5 & \\
\hline
\end{tabular}

Table 2. Comparison of experimental and analytical results (Frequency ratio $=9.315$ ) 
A detailed modal testing is conducted using LMS SCADAS -III/ CADA-X/Modal Analysis software. The model is subjected to $50 \%$ burst random force and the responses are therefore measured by the accelerometers. The transfer function technique is adopted to extract the natural frequencies, associated mode shapes and the corresponding damping values of various modes of the model (refer to table 2 and figures 8,9 ).

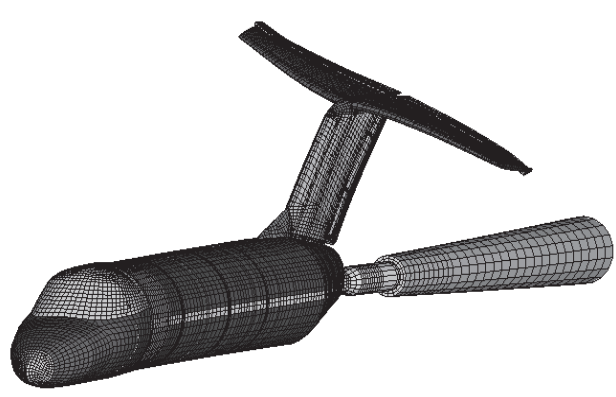

(a) HTP Anti-symmetric bending

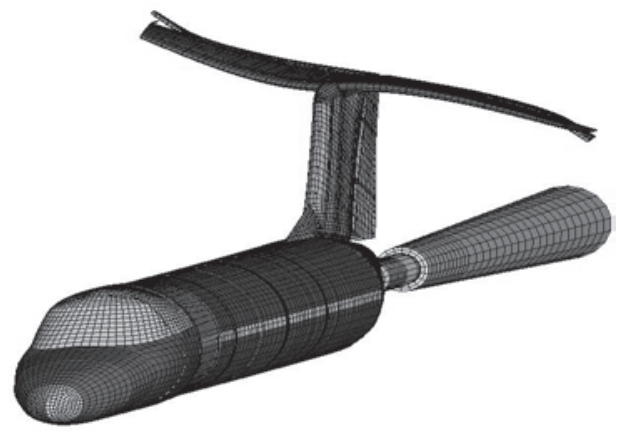

(c) VTP lateral bending

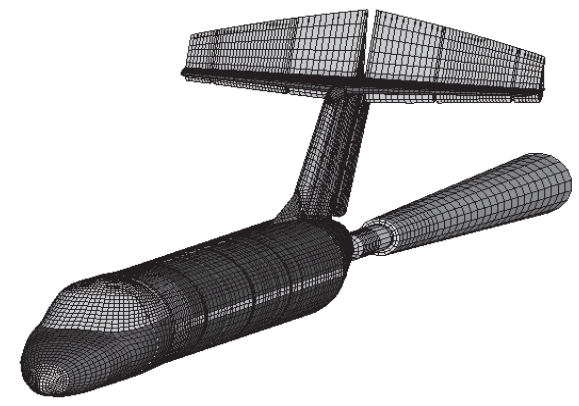

(b) Elevator rotation

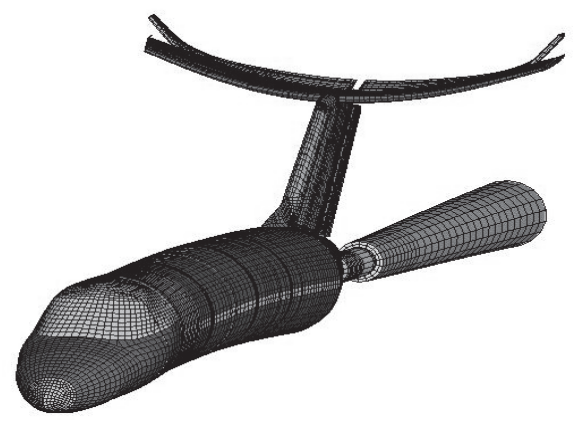

(d) HTP Symmetric bending

Fig. 7. FE analysis based mode shapes of the model

\subsection{Divergence clearance}

Since the model supporting system is slender body, it demands clearance from divergence instability prior to the wind tunnel testing (Sundara Murthy, 2005).

The following data are used in the static divergence calculation.

- Values of lift and moment coefficients for different angles of attack

- $\quad$ Centre of pressure (Cp)

for the Mach number and dynamic pressure of interest.

In order to calculate the divergence parameters, the sting and adapter assembly is loaded at $\mathrm{Cp}$ and as well as at its tip (equivalent static aerodynamic load $\approx 50 \mathrm{~kg}, \mathrm{C}_{\mathrm{L}}=1.0$ ). The deflections are measured at the strain gauge locations (reaction points). Using the following relations (Sundara Murthy, 2005), the divergence parameters are estimated as follows: 
$\mathrm{D}=\mathrm{qS}\left[\left(l_{R} C_{M \alpha}+x C_{N \alpha}\right)\left(\frac{\delta_{N 1}-\delta_{N 2}}{l_{N}}\right)+C_{N \alpha}\left(\frac{\delta_{N 1}+\delta_{N 2}}{2}\right)\right]$

$\mathrm{D}=0.125<0.2$.

$$
\begin{aligned}
& \Delta \theta=\frac{\left(\mathrm{D} \alpha_{0}+\mathrm{C}_{0}\right)}{(1-D)}, \\
& \mathrm{C}_{0}=\mathrm{qS}\left[\left(l_{R} C_{M 0}+x C_{N 0}\right)\left(\frac{\delta_{N 1}-\delta_{N 2}}{l_{N}}\right)+C_{N 0}\left(\frac{\delta_{N 1}+\delta_{N 2}}{2}\right)\right],
\end{aligned}
$$

$\Delta \theta=0.5278^{\circ}<3^{\circ}$.
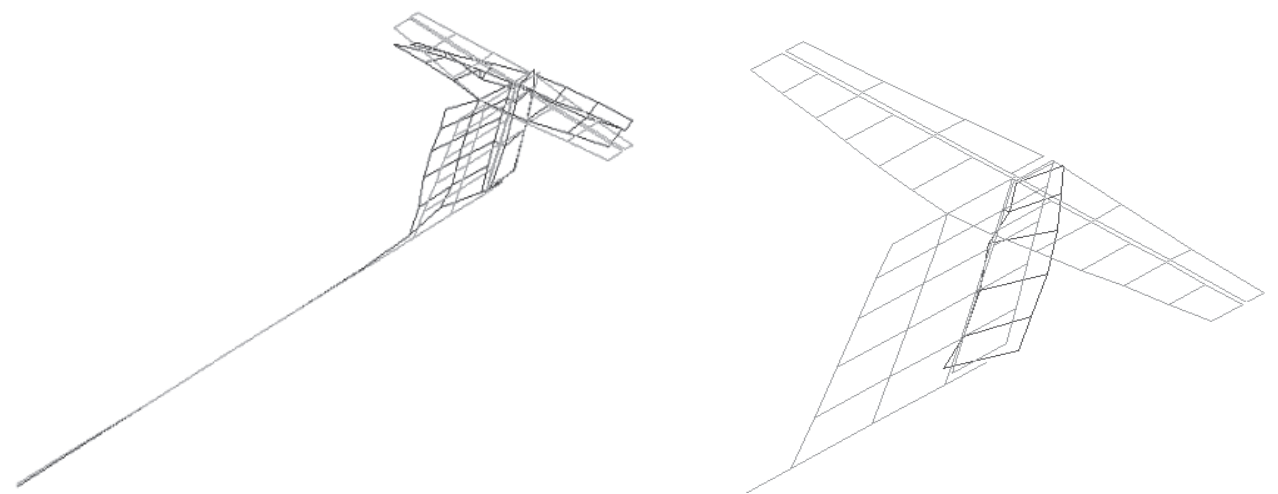

(a) HTP anti-symmetric bending (b) Rudder rotation
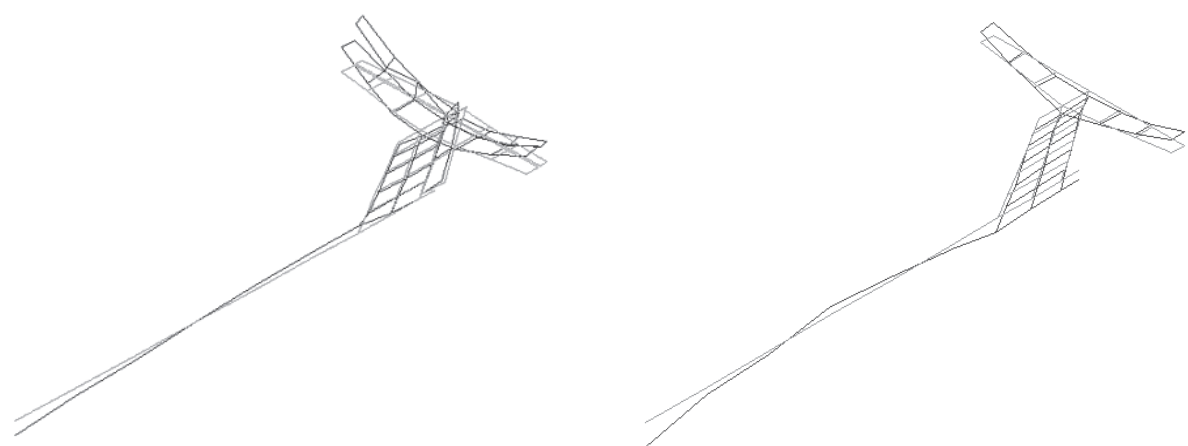

(c) HTP symmetric bending (d) Fuselage bending

Fig. 8. Few experimental mode shapes (GVT)

It has been seen that the supporting system is free from the static divergence instability in the proposed test envelope. 


\section{Wind tunnel testing}

The wind tunnel testing is done, following the dynamic pressure variation as shown in table 3. The model needs to show flutter free condition in order to qualify the full scale T-Tail for a Mach number of 0.42 .

\begin{tabular}{|l|l|l|l|l|l|l|}
\hline Mach No & 0.2 & 0.25 & 0.3 & 0.35 & 0.4 & 0.45 \\
\hline qdynamic (PSI) & 1.36 & 2.1 & 2.95 & 3.94 & 5.0 & 6.16 \\
\hline
\end{tabular}

Table 3. Wind tunnel test matrix

The 10\% aircraft T-Tail model has been tested in $1.2 \mathrm{~m}$ wind tunnel (refer to figure 10). The aeroelastic scale parameters are applied to obtain a replica model through optimization process for the full scale T-Tail configuration. It has been shown through ground vibration testing that the necessary dynamic characteristics have been achieved fairly by the fabricated model (see table 2). The longitudinal fuselage mode has been simulated along with the sting bending mode. This is observed to be a quite reasonable simulation from the complexity point of view of simulating a free-free boundary effect through spring-sting arrangement. The tunnel tests are completed with 22 runs (blow downs) to cover the required dynamic pressure and Mach number range. During the wind tunnel testing, the data has been collected through 'Throughput Acquisition Monitor' of LMS® for multiple channels concurrently (refer to figure 11). The measured aeroelastic data from the accelerometers, positioned at different locations is processed with 'Operational Modal Analysis' software of LMS®. This software has got computational algorithms such as poly reference and balanced realization etc, using which the damping is estimated. The frequencies and damping values obtained from the flutter experiments are presented, following classical V-g approach in figure 12.

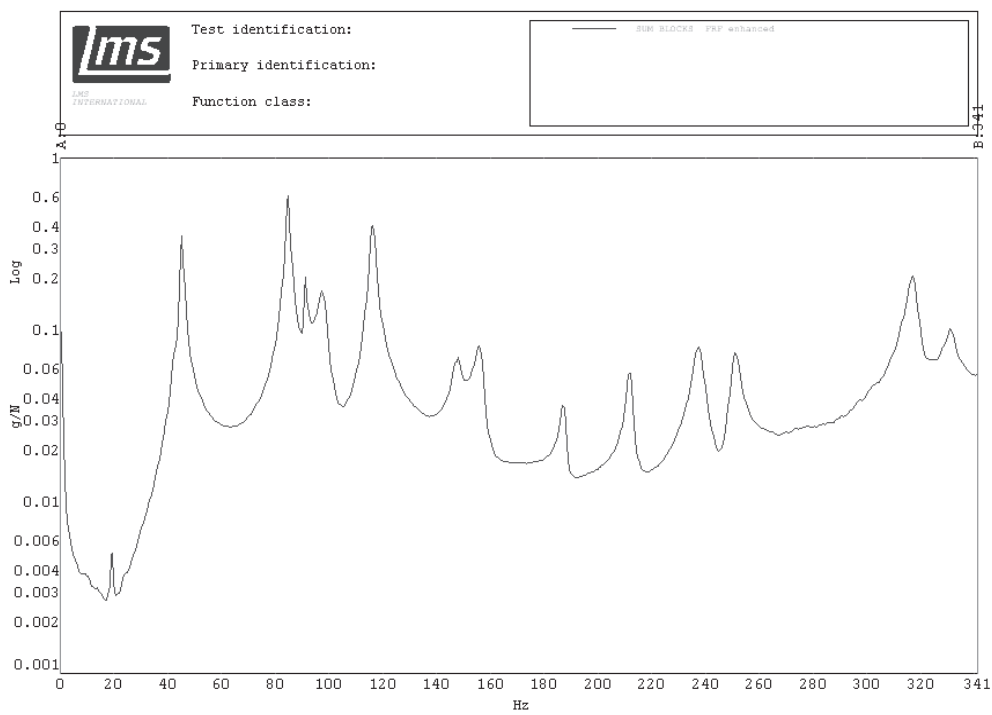

Fig. 9. Modal response during GVT 


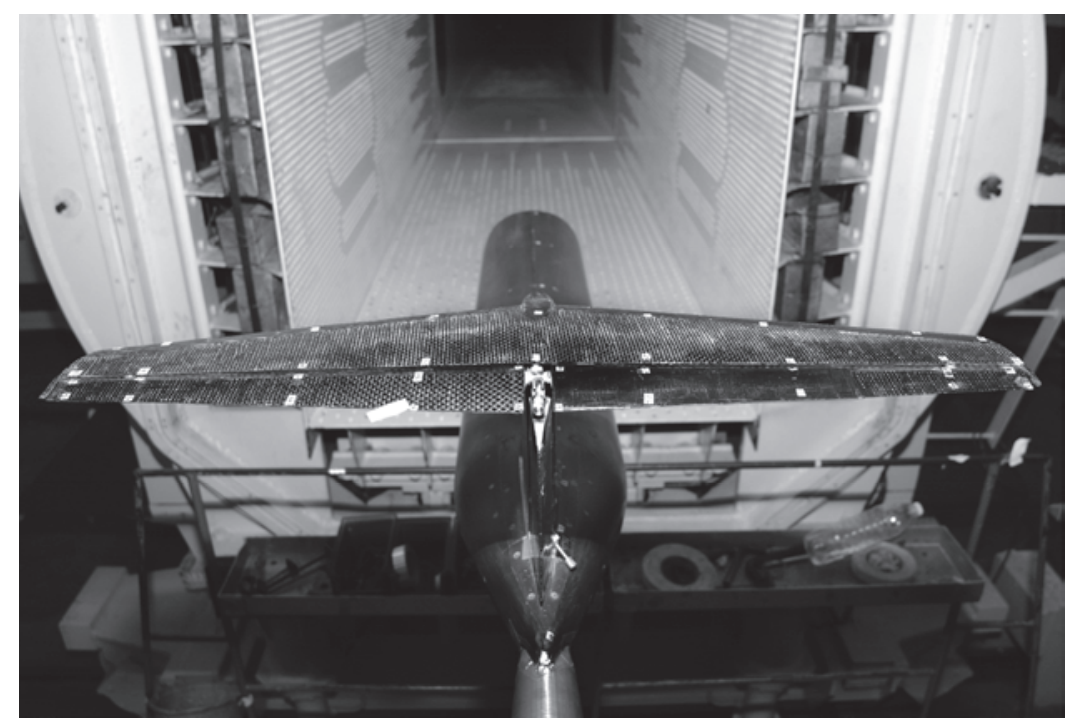

Fig. 10. Aircraft model in wind tunnel

\section{Observations}

- The aircraft model is tested in the Mach range of 0.2 to 0.45

- The T-Tail has not shown any trend of flutter in the tested Mach numbers and dynamic pressures, thus qualify from flutter in the aircraft flight envelope

- Test results have shown that HTP-Symmetric bending and VTP-in-plane bending modes have nearly $2 \%$ aerodynamic damping at maximum test dynamic pressure (5 PSI) in addition to structural damping

- Fuselage longitudinal bending mode does not appear to be influenced by aerodynamic damping and the mode shows a nearly constant structural damping

\section{Conclusion}

This research work presents the details of fabrication, ground and wind tunnel testing of a scaled aeroelastic model of T-Tail with a flexible fuselage. Using composite materials and optimization procedures the required dynamics, namely frequencies and mode shapes of the T-Tail are achieved, which includes two control surface modes. After conducting a thorough ground studies, the model has been tested in $1.2 \mathrm{~m}$ Trisonic Wind Tunnel for the flutter clearance of T-Tail in the subsonic aerodynamic regime. The flutter characteristics are obtained as classical velocity versus damping and velocity versus frequency plots. The flutter experiments are carried out to cover a Mach range of 0.2 to 0.45 . The critical modes of the T-Tail have not shown any dynamic instability nature at critical flight velocity 141.33 $\mathrm{m} / \mathrm{sec}$. Also, the total damping (Structural and Aerodynamic) of the critical modes are noticed to be around $2 \%$. This fact has ensured that the T-Tail is qualified from flutter at maximum diving velocity. 

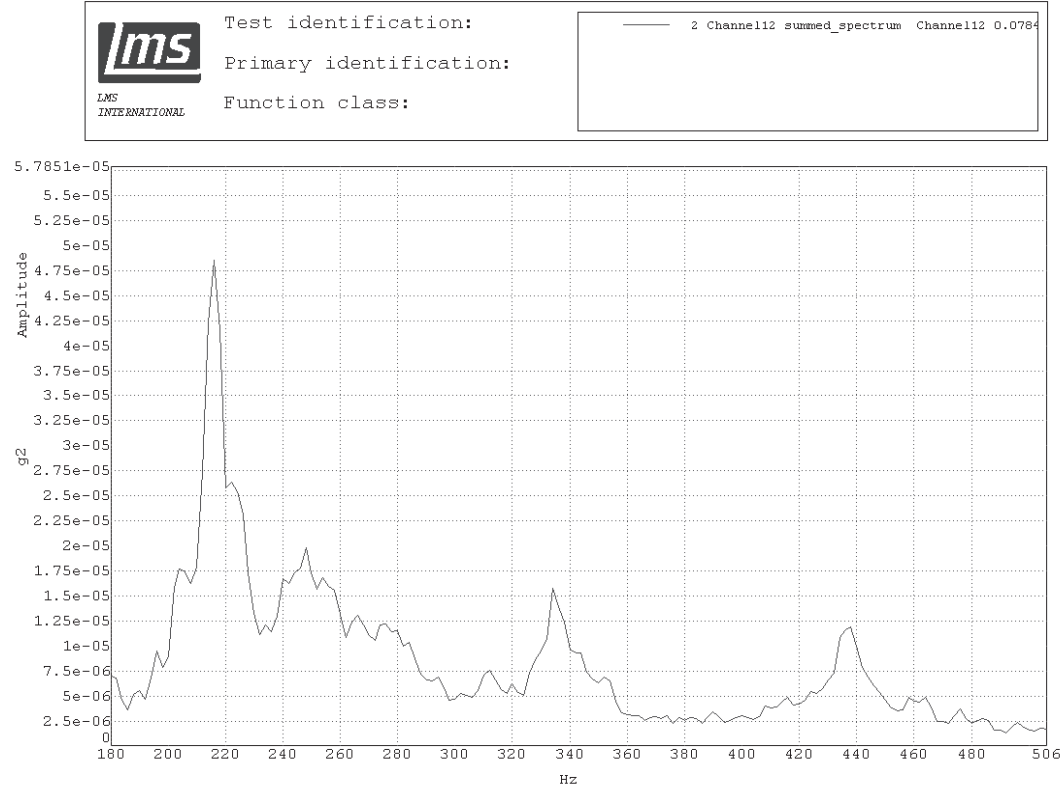

(a)

\section{ms \\ Test identification:}

LMS Function class:autopower_spectr

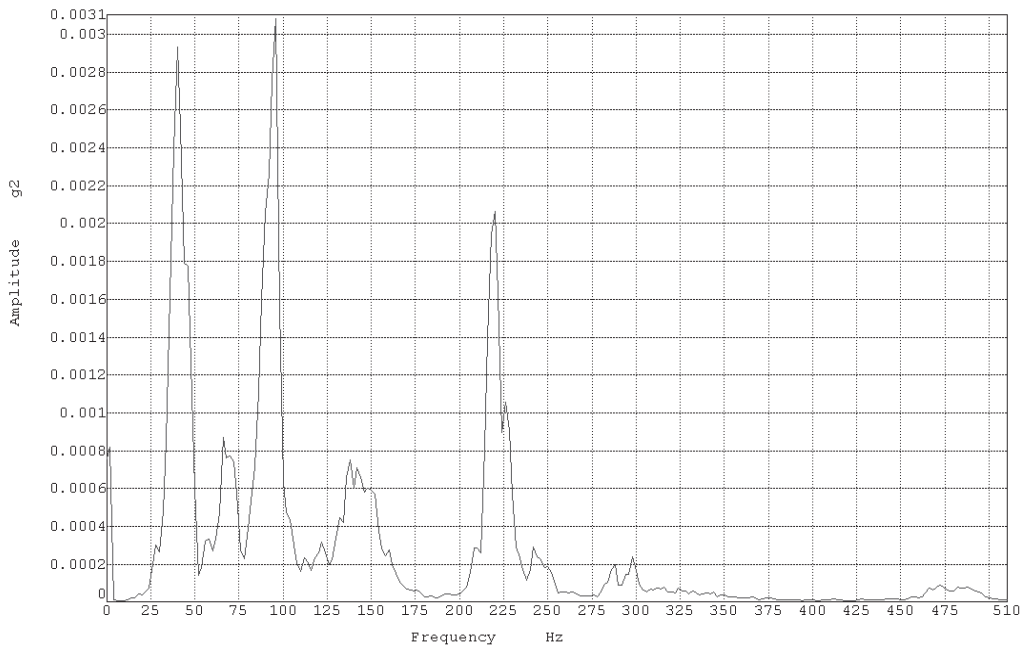

(b)

Fig. 11. Wind tunnel test results 


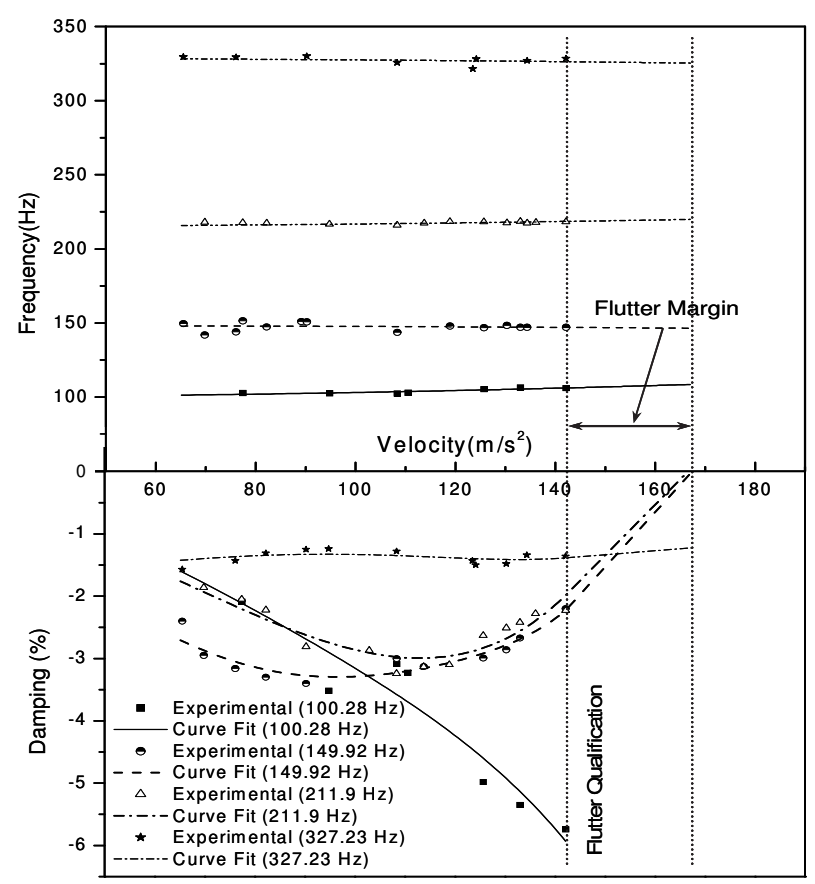

Fig. 12. Velocity vs. frequency and damping for critical modes

\section{Acknowledgment}

The authors wish to thank the contributors of this team work, namely Mrs. Shashikala Rajappa, Mr. D Sundararajan, Mr. S Janardhanam, Mrs. Annamma Samuel, Mr. Mutturaj H Medar and Mr. D Dwarakanathan, Scientists, Structural Technologies Division, National Aerospace Laboratories (NAL). Thanks are due to Mr. Ramachandra and his team, EAD, for their excellent fabrication work towards realizing the 10 percent aeroelastic model. We also would like to appreciate the Scientists of NTAF, NAL for their technical coordination and contribution. The fabrication of metallic parts from ESD, NAL has been duly acknowledged.

\section{Nomenclature}

$\mathrm{L}_{\mathrm{m}} \quad=$ Length of the model

$\mathrm{L}_{\mathrm{p}} \quad$ = Length of the full scale vehicle

$\mathrm{q}_{\mathrm{m}} \quad=$ Dynamic pressure in the tunnel

$\mathrm{q}_{\mathrm{p}} \quad=$ Flight dynamic pressure

$\mathrm{V}_{\mathrm{m}}=$ Velocity of flow in the tunnel

$\mathrm{V}_{\mathrm{p}} \quad=$ Flight velocity

$\rho_{\mathrm{m}} \quad=$ Density of air in the tunnel

$\rho_{\mathrm{p}} \quad=$ Density of air at flight altitude

$\mathrm{W}_{\mathrm{m}}=$ Weight of the model
Subscripts:

$\mathrm{m}=$ model

$\mathrm{p}=$ proto

GVT = ground vibration testing

FS =Front spar

MS = Middle spar

RS = Rear spar

HTP $=$ Horizantal tail plane

$\mathrm{VTP}=$ Vertical tail plane 
$\mathrm{W}_{\mathrm{p}}=$ Weight of the vehicle

$\Omega_{\mathrm{m}} \quad=$ Frequency of the model

$\Omega_{\mathrm{p}} \quad=$ Frequency of the vehicle

$\delta_{\mathrm{m}} \quad=$ Deflection on the model

$\delta_{\mathrm{p}} \quad=$ Deflection on the full scale vehicle

EI = Bending rigidity

EA $=$ Axial stiffness

$\mathrm{D}=$ Static divergence parameter

$\Delta \theta=$ Angular deflection of model-balance sting system

$\mathrm{q} \quad=$ Dynamic Pressure

$\mathrm{S}=$ Reference area (Projected area of Fuselage, HTP and Elevator)

$C_{N \alpha}=$ Local slope of $C_{L}$ vs $\alpha$ plot at $\alpha=5^{\circ}$

$C_{M \alpha}=$ Local slope of $C_{M}$ vs $\alpha$ plot at $\alpha=5^{\circ}$

$C_{M o}=$ Intercept of the tangent to $C_{M}$ vs $\alpha$ plot

$C_{N o}=$ Intercept of the tangent to $C_{L}$ vs $\alpha$ plot

$l_{N} \quad=$ Distance between front and rear attachment points

$l_{R} \quad=$ Reference length of pitching moment coefficient

$\mathrm{x} \quad=$ Distance between $\mathrm{C}_{\mathrm{p}}$ and centre balance attachment point

$\delta_{N 1}=$ Deflection per unit normal force at front attachment point

$\delta_{N 2}=$ Deflection per unit normal force at rear attachment point

$\alpha_{0} \quad=$ Initial angle of attack of the model

$C_{L} \quad=$ Lift coefficient

$C_{M}=$ Pitching moment coefficient

$\alpha \quad=$ Angle of attack

\section{References}

Upadhya, A. R. et al. (November 1985). Aeroelastic Testing of ASLV Models for Predicting Transonic Buffet Response- Wind Tunnel Testing and Data Analysis, NAL PD-ST 8523.

Joshi A. et al. (December 1988). Aeroelastic Testing of PSLV Models, NAL PD-ST 8833.

Rama Murthy, M. R. and Raja, S. (July 2002). Aeroelastic Testing on LCA Wing Model with R73E Missile, NAL PD ST 0212.

Raja, S. et al. (May 2007). Transonic Buffet Response Study of gsLVM3 through Aeroelastic Model Testing : Wind Tunnel Testing and Data Analysis, NAL PD-ST 0712.

Bisplinghoff, R. L., Ashley, H. \& Halfman, R. L. (1983). Aeroelasticity, Addison - Wesley Publishing Company Inc.

Queijo, M. J. (1968). Theory for computing span loads and stability derivatives due to sideslip, yawing, and rolling for wings in subsonic compressible flow, NASA TN D-4929.

Sundara Murthy, H. (March 2005). A Method for Static Divergence Analysis of Sting Mounted Wind Tunnel Models, NAL PD NT 0508.

Megson, T. H. G. (2007). An Introduction to Aircraft Structural Analysis, Elsevier Pub. 


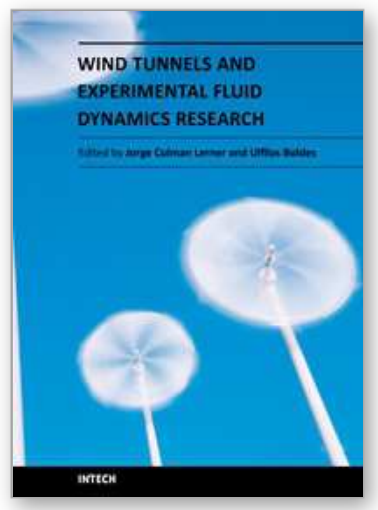

\author{
Wind Tunnels and Experimental Fluid Dynamics Research \\ Edited by Prof. Jorge Colman Lerner
}

ISBN 978-953-307-623-2

Hard cover, 709 pages

Publisher InTech

Published online 27, July, 2011

Published in print edition July, 2011

The book â€œWind Tunnels and Experimental Fluid Dynamics Researchâ€ is comprised of 33 chapters divided in five sections. The first 12 chapters discuss wind tunnel facilities and experiments in incompressible flow, while the next seven chapters deal with building dynamics, flow control and fluid mechanics. Third section of the book is dedicated to chapters discussing aerodynamic field measurements and real full scale analysis (chapters 20-22). Chapters in the last two sections deal with turbulent structure analysis (chapters 23-25) and wind tunnels in compressible flow (chapters 26-33). Contributions from a large number of international experts make this publication a highly valuable resource in wind tunnels and fluid dynamics field of research.

\title{
How to reference
}

In order to correctly reference this scholarly work, feel free to copy and paste the following:

Raja Samikkannu (2011). Wind Tunnel Flutter Testing of Composite T-Tail Model of a Transport Aircraft with Fuselage Flexibility, Wind Tunnels and Experimental Fluid Dynamics Research, Prof. Jorge Colman Lerner (Ed.), ISBN: 978-953-307-623-2, InTech, Available from: http://www.intechopen.com/books/wind-tunnels-andexperimental-fluid-dynamics-research/wind-tunnel-flutter-testing-of-composite-t-tail-model-of-a-transportaircraft-with-fuselage-flexibil

\section{INTECH}

open science | open minds

\section{InTech Europe}

University Campus STeP Ri Slavka Krautzeka 83/A

51000 Rijeka, Croatia Phone: +385 (51) 770447

Fax: +385 (51) 686166

www.intechopen.com

\author{
InTech China \\ Unit 405, Office Block, Hotel Equatorial Shanghai \\ No.65, Yan An Road (West), Shanghai, 200040, China \\ 中国上海市延安西路65号上海国际贵都大饭店办公楼 405 单元 \\ Phone: +86-21-62489820 \\ Fax: +86-21-62489821
}


(C) 2011 The Author(s). Licensee IntechOpen. This chapter is distributed under the terms of the Creative Commons Attribution-NonCommercialShareAlike-3.0 License, which permits use, distribution and reproduction for non-commercial purposes, provided the original is properly cited and derivative works building on this content are distributed under the same license. 